\title{
FLUORESCENCE STUDIES ON PHOTOSYNTHETIC PIGMENT DEVELOPMENT IN RHODOPSEUDOMONAS SPHEROIDES*†
}

\author{
R. A. CELLARIUS and G. A. PETERS \\ Department of Botany and Mental Health Research Institute, The University of Michigan, \\ Ann Arbor, Michigan 48104, U.S.A.
}

(Received 25 August 1967; in revised form 23 October 1967)

\begin{abstract}
When bleached, aerobically grown cells of Rhodopseudomonas spheroides are transferred to semi-aerobic conditions to induce bacteriochlorophyll synthesis, a new fluorescence band, with a maximum at $790 \mathrm{~nm}$, is observed in addition to the $885 \mathrm{~nm}$ emission maximum normally seen in pigmented cells. The $790 \mathrm{~nm}$ fluorescence may be due to bacteriochlorophyll which has not been bound into the chromatophore membrane. The quantum yield of the $885 \mathrm{~nm}$ fluorescence is at first relatively high and then, about 1 hour after transfer, drops to the level found in pigmented photosynthetic cells. The coupling to the rest of the photosynthetic apparatus, as indicated by the effect of dithionite on the fluorescence, also seems to occur during the first hour of pigment development, which suggests that the onset of fluorescence quenching is due at least in part to the synthesis of photochemical reaction centers. Continuation of these studies should provide new information on the formation, structure and molecular interactions of the pigments and the photosynthetic membranes.
\end{abstract}

\section{INTRODUCTION}

Most approaches to the study of photosynthesis have involved the use of relatively mature material, either from photosynthetic bacteria or, more frequently, from algae or higher plants. Such studies have indicated that the primary energy-conversion reactions involve light-activated oxidation-reduction reactions of the specialized chlorophyll and surrounding molecules at the photosynthetic reaction center[1-3]. In addition, partial purification of the reaction center pigments, P700 in higher plants [4] and P870 in bacteria [5], has been achieved. However, these studies have not indicated why the properties of the chlorophyll at the reaction center are different from those of the remaining bulk chlorophyll, what the primary electron acceptors are, or why the primary photochemical reactions are so efficient. We feel that the use of developing material can provide new insights into the nature of the chemical and structural relationships at the reaction center, and for this reason we have been studying the development of the photosynthetic apparatus in bacteria. Similar studies have been done with higher plants showing, for example, the formation of several forms of chlorophyll in vivo [6,7], and the development of the capacity for energy transfer[8] and photosynthesis [9-12] during the early stages of the greening process. These studies provide a striking parallel to the results described in this paper. The bacteria, in addition, would appear to provide a more controllable and accessible system for studying the above questions.

\footnotetext{
*Supported in part by a grant from the National Institutes of Health (GM 14035) to Professor J. R. Platt and a grant from the University of Michigan Cancer Research Institute.

$\dagger$ Abbreviation: Rps.; Rhodopseudomonas.
} 
Rps. spheroides, one of the nonsulfur, purple photosynthetic bacteria, grows either photosynthetically under anaerobic conditions or heterotrophically, without the production of photosynthetic pigments, under aerobic conditions. In the studies described below, we have been concerned with the changes in fluorescence which occur during the early stages of bacteriochlorophyll synthesis as 'bleached', aerobically grown cells repigment. The kinetics of pigment and protein synthesis during this process have previously been characterized[13-15]. We have concentrated on the fluorescence properties of bacteriochlorophyll in vivo because fluorescence provides a sensitive means of detecting small quantities of pigment as well as a sensitive measure of the changes in the environment of the molecules being studied.

\section{MATERIALS AND METHODS}

The green mutant of Rps. spheroides (strain $2.4 .1 / \mathrm{Ga}$; obtained from Dr. R. K. Clayton) was grown on modified Hutner's medium [13]. This medium is used for growth under photosynthetic, aerobic or semi-aerobic conditions.

The repigmentation studies were performed as follows: A thoroughly bleached, aerobically grown culture, in an early stage of logarithmic growth, was bubbled with nitrogen for $\mathbf{3 0} \mathrm{min}$ to deplete the culture of oxygen and to provide a relatively sharp changeover to pigment synthesis. The culture was then grown under semi-rerobic conditions (vigorous bubbling with 4 per cent oxygen in nitrogen) in the dark to induce pigmentation. At various times aliquots of the culture were removed and the fluorescence spectrum of the cells in the growth medium determined. The effects of dithionite was determined by measuring the increase in fluorescence on adding about $1 \mathrm{mg} / \mathrm{ml}$ dithionite to the sample. These samples were then centrifuged at $12,000 \mathrm{~g}$ for $10 \mathrm{~min}$ at $0^{\circ} \mathrm{C}$ to sediment the cells which were then extracted with $2 / 7(\mathrm{v} / \mathrm{v})$ methanol/acetone. The fluorescence spectra of the extracts were then determined.

Fluorescence emission spectra were obtained using an EMI 9684A photomultiplier tube, cooled with dry-ice, and a Jena interference-wedge filter (model Veril SL-200, bandpass about $14 \mathrm{~nm}$ ) together with a scanning drive, power supply, amplifier and strip chart recorder. The wedge scanning drive consists of a stepping motor driven by a Heath multispeed drive unit in synchrony with the chart drive on the Heath recorder such that the scanning speed can be varied while maintaining a constant ratio between chart and wedge movement. The spectra have not been corrected for the spectral response of the photomultiplier-wedge combination. Excitation was from a tungsten lamp and was filtered through a solution of $\mathrm{CuSO}_{4}$ and $\mathrm{CrO}_{3}$ so as to excite only the $590 \mathrm{~nm}$ absorption band of the bacteriochlorophyll (excitation intensity about $7 \times 10^{3}$ $\mathrm{ergs} / \mathrm{cm}^{2}$-sec).

\section{RESULTS AND DISCUSSION}

Representative fluorescence emission spectra are shown in Fig. 1. The emission spectrum of photosynthetically grown, pigmented cells shows only the prominent bacteriochlorophyll fluorescence at $885 \mathrm{~nm}$. In the spectrum of the totally depigmented, aerobically grown cells, shown on a 100 times more sensitive scale, there is less than $1 / 10^{4}$ of the fluorescence of normal cells detectable at the bacteriochlorophyll maximum. In order to achieve such complete depletion of the bacteriochlorophyll, it is necessary 


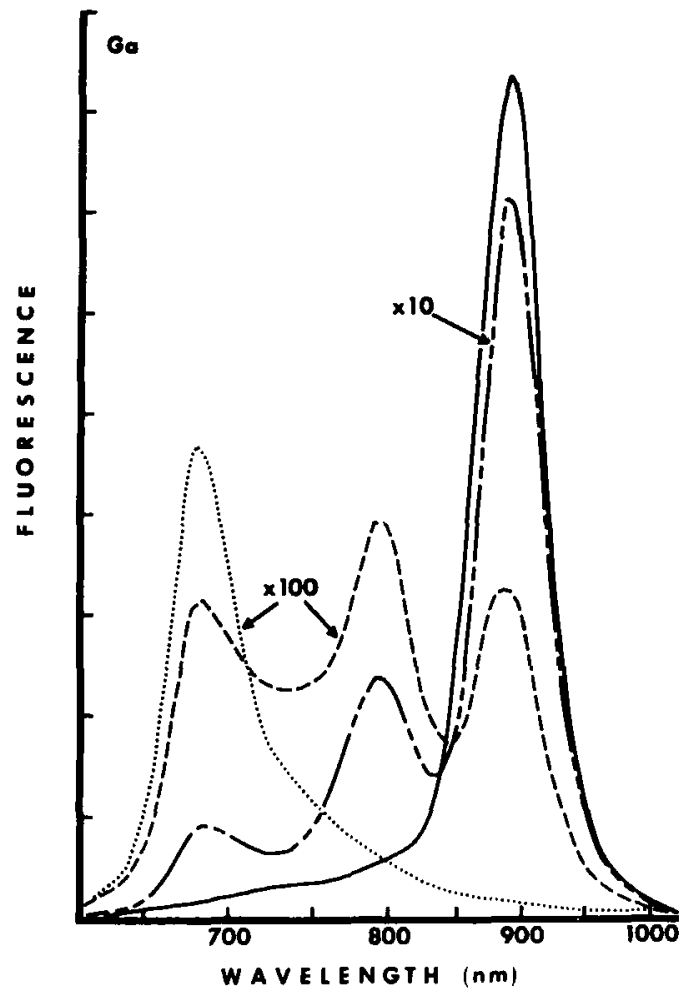

Fig. 1. Fluorescence emission spectra of Rps. spheroides cells at various stages of pigmentation: photosynthetically grown, pigmented cells; .... bleached, aerobically grown cells; - - - bleached cells grown semi-aerobically for 40 minutes; __ _ _ - bleached cells grown semi-aerobically for $3 \frac{1}{4} \mathrm{hr}$.

to grow the cultures under vigorous aeration in the light, maintaining the culture in a logarithmic growth phase 15-20 generations. If cells are grown aerobically in the dark, they form measurable bacteriochlorophyll $[13,14]$. The peak at $680 \mathrm{~nm}$ in the bleached cells is probably due either to scatter from the exciting beam or to an early intermediate of porphyrin biosynthesis such as coproporphyrin.

If bleached cells are placed in the light in anaerobic conditions, they take $24-36 \mathrm{hr}$ to produce detectable pigment. But if they are transferred to semi-aerobic conditions in the dark, bacteriochlorophyll fluorescence is detectable as early as 10-15 min after transfer. Figure 1 also shows the fluorescence spectra of cells after 40 min and after $3 \frac{1}{4} \mathrm{hr}$ of semi-aerobic growth starting from the bleached state. In addition to the normal bacteriochlorophyll fluorescence, a second fluorescence band has appeared at $790 \mathrm{~nm}$. To our knowledge this $790 \mathrm{~nm}$ fluorescence has not been observed previously.

The intensities of the $790 \mathrm{~nm}$ and $885 \mathrm{~nm}$ maxima are shown as a function of time in Fig. 2. As mentioned above, the bacteriochlorophyll begins to appear very soon after transfer to semi-aerobic conditions. During early stages of development, the $790 \mathrm{~nm}$ peak is slightly more intense than the bacteriochlorophyll peak at $885 \mathrm{~nm}$; however, it falls behind after the first hour of growth. The time course of bacteriochlorophyll synthesis we observe agrees well with the original results of Cohen-Bazire, Sistrom and Stanier[13]: After about $6 \mathrm{hr}$ the rate of increase of bacteriochlorophyll 


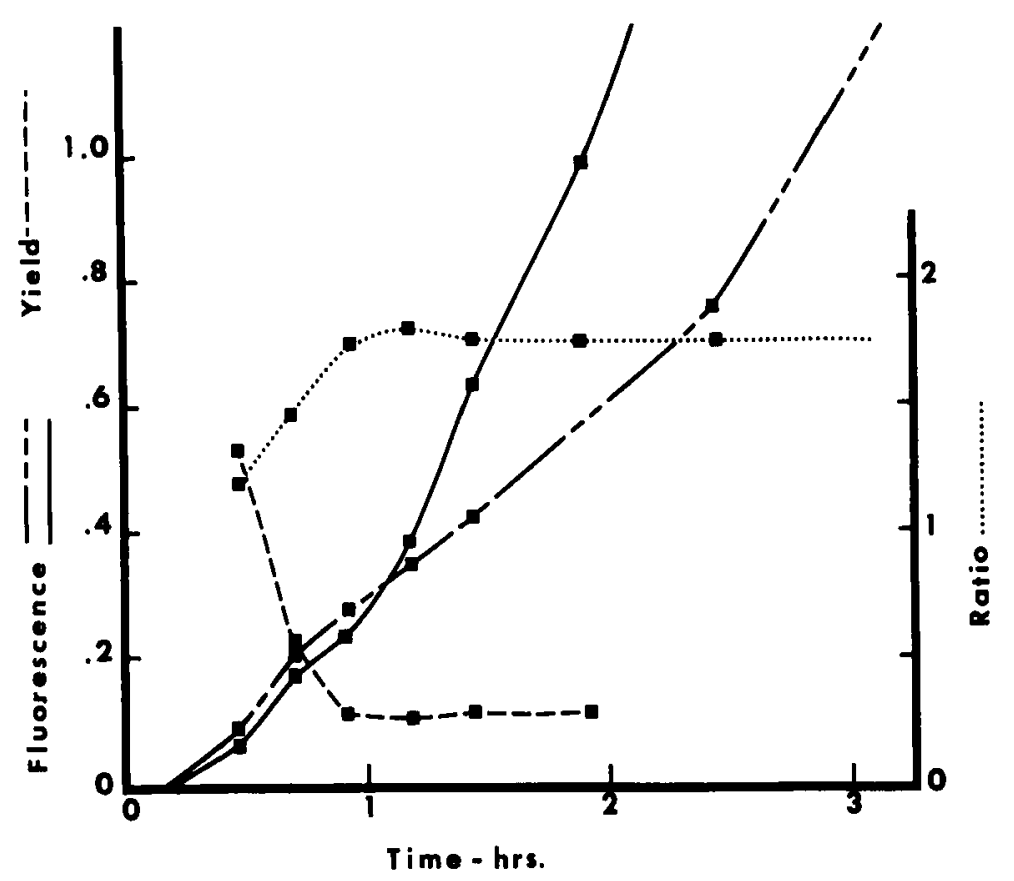

Fig. 2. The increase of the fluorescence intensity at $790 \mathrm{~nm}$ and $885 \mathrm{~nm}$ and the changes in fluorescence yield in an initially bleached culture growing semi-aerobically: - fluorescence intensity at $885 \mathrm{~nm}$; — - — fluorescence intensity at $790 \mathrm{~nm}$; - - relative fluorescence yield or ratio of the intensity of the $885 \mathrm{~nm}$ fluorescence in vivo to that of the $785 \mathrm{~nm}$ maximum in a methanol/acetone extract of the same cells (corrected as described in the text); ... ratio of the fluorescence intensity at $885 \mathrm{~nm}$ in vivo after addition of dithionite to that before.

fluorescence begins to slow down and parallels the growth rate of the culture (doubling time of about $3.5 \mathrm{hr}$ ).

The $790 \mathrm{~nm}$ fluorescence maximum is near that of bacteriochlorophyll in solution $(785 \mathrm{~nm}$ in methanol/acetone). In the extract of the pigment from cells in which the $790 \mathrm{~nm}$ peak is prominent, such as those shown in Fig. 1 which have been growing semi-aerobically for $40 \mathrm{~min}$, only one fluorescence peak is seen and the emission spectrum appears to be identical with that of pure bacteriochlorophyll. These data suggest that the $790 \mathrm{~nm}$ fluorescence is due to bacteriochlorophyll which has not yet been bound to the photosynthetic membranes. Because of the relatively broad spectral bandpass of the interference wedge, we cannot as yet preclude the possibility that this fluorescence is due to another compound, such as a precursor of bacteriochlorophyll, whose fluorescence maximum in vitro is very close to that of bacteriochlorophyll itself. Further studies on the origin and fate of this fluorescing species may tell us specifically the form in which the bacteriochlorophyll is incorporated into the membrane.

The quantum yield of bacteriochlorophyll fluorescence in vivo is a function of the relationship between the bacteriochlorophyll and the other components of the photosynthetic membranes. One useful measure of the changes in this yield is the ratio of the intensity of the $885 \mathrm{~nm}$ fluorescence peak in vivo to that of the $785 \mathrm{~nm}$ peak in methanol/ acetone (corrected by subtracting the intensity of the $790 \mathrm{~nm}$ peak in vivo) since we can assume that the yield in solution is fixed. In normally pigmented cells this ratio is about 
$0 \cdot 1$. The changes in the yield of bacteriochlorophyll fluorescence which occur during the first few hours of repigmentation are shown in Fig. 2. At first, the fluorescence yield decreases and only after an hour does the ratio reach a value of 0.1 and level off. The drop in fluorescence yield as the amount of pigment increases resembles the results obtained by Goedheer[16] in greening bean leaves, where the ratio of fluorescence in vivo to that in an extract dropped to 0.1 four hours after the induction of chlorophyll synthesis. Similar results were reported by Tweet, Gaines and Bellamy[17] and Cellarius and Mauzerall[18] for model systems containing chlorophyll or pheophytin. In those experiments, the fluorescence yield dropped to 0.1 of that in dilute solution only when the pigment concentration was increased to cover 10 per cent of the available surface area either in a mixed monomolecular film or on polystyrene particles.

The decrease in the fluorescence yield as the chlorophyll is put into the photosynthetic membranes could be due either to the interaction and aggregation of the pigment molecules alone, as is the case in the model systems [18], or to the simultaneous development of and coupling with the enzymatic machinery, which then uses the light energy for photosynthesis, rather than wasting it as fluorescence. The latter is certainly the case in mature photosynthetic cells and the following data suggest it is also true for the repigmenting cells.

Clayton[19] has reported that the addition of dithionite to photosynthetic cells causes an approximately two-fold increase in bacteriochlorophyll fluorescence. This effect is presumably due to the reduction of the primary electron acceptors, which blocks the photochemical reactions and forces the energy out as excess fluorescence $[19,20]$. The effect of dithionite on the intensity of the $885 \mathrm{~nm}$ fluorescence maximum in repigmenting cells is also shown in Fig. 2. Initially there is only a small effect, as measured by the ratio of the fluorescence after addition to that before addition of dithionite, but after an hour dithionite increases the fluorescence to the same extent as in fully pigmented cells. The onset of the maximum dithionite effect correlates exactly with the onset of the quenching of the fluorescence in vivo, which suggests that the quenching is due to an interaction with the enzymatic machinery and that this interaction is established very early during the repigmentation process. Since there is a lag, it is clear that the first bacteriochlorophyll synthesized does not associate immediately with functional photosynthetic reaction centers.

We have also observed that $6 \times 10^{-3} \mathrm{M}$ Seconal, an inhibitor of mitochondrial electron transport, will cause an increase in the fluorescence of whole cells of $R p s$. spheroides, and that its effect on repigmenting cells has an induction period during development similar to that observed with dithionite. We have also found that this concentration of Seconal will almost completely inhibit most of the known photosynthetic reactions in both Rps. spheroides and Rhodospirillum rubrum chromatophores. ${ }^{*}$ These data support the conclusions above regarding the relationship between the fluorescence quenching and the synthesis of functional reaction centers.

While suggesting that the photosynthetic reaction centers become functional soon after pigment synthesis begins, the data above do not indicate the extent to which these centers are preformed in bleached cells nor whether they attain maximum photosynthetic efficiency immediately on being synthesized. Further work on the kinetics of

\footnotetext{
*Unpublished experiments performed at the C. F. Kettering Research Laboratory, Yellow Springs, Ohio. We thank Drs. L. P. Vernon, A. F. Garcia, C. W. Jones, D. L. Keister, and D. E. Fleischman for assistance in these experiments.
} 
the synthesis of reaction centers, on the nature and fate of the component giving rise to the $790 \mathrm{~nm}$ fluorescence and on the quantum yield of photosynthesis in the repigmenting cells should help to answer these questions.

Acknowledgements - We would like to thank Dr. J. L. Oncley of the Biophysics Research Division, Institute of Science and Technology, The University of Michigan, for providing laboratory facilities and Dr. John R. Platt and Dr. Robert E. Beyer for advice and discussion during the course of this work.

\section{REFERENCES}

1. L. P. Vernon, Ann. Rev. Plant Physiol. 15, 73 (1964).

2. Energy Conversion by the Photosynthetic Apparatus. Brookhaven Symp. Biol. 19 (1966).

3. R. K. Clayton, Science 149, 1346 (1965).

4. B. Kok, Biochim. et Biophys. Acta 48, 527 (1961).

5. R. K. Clayton, Brookhaven Symp. Biol. 19,62 (1966).

6. K. Shibata, J. Biochem. 44, 147 (1957).

7. W. L. Butler and W. R. Briggs, Biochim. et Biophys. Acta 112, 45 (1966).

8. W. L. Butler, Arch. Biochem. Biophys. 92, 287 (1961).

9. J. H. C. Smith, Plant Physiol. 29, 143 (1954).

10. J. M. Anderson and N. K. Boardman, Australian J. Biol. Sci. 17, 93 (1964).

11. A. I. Stern, J. A. Schiff and H. T. Epstein, Plant Physiol. 39, 220 (1964).

12. W. L. Butler, Biochim. et Biophys. Acta 102, 1 (1965).

13. G. Cohen-Bazire, W. R. Sistrom and R. Y. Stanier, J. Cellular Comp. Physiol. 49, 25 (1959).

14. J. Lascelles, Biochem. J. 72, 508 (1959).

15. W. R. Sistrom, J. Gen. Microbiol. 28, 607 (1962).

16. J. C. Goedheer, Biochim. et Biophys. Acta 51, 494 (1954).

17. A. G. Tweet, G. L. Gaines, Jr. and W. D. Bellamy, J. Chem. Phys. 40, 2596 (1964).

18. R. A. Cellarius and D. Mauzerall, Biochim. et Biophys. Acta 112, 235 (1966).

19. R. K. Clayton, Photochem. Photobiol. 5,679 (1966).

20. I. P. Kuntz Jr., P. A. Loach and M. Calvin, Biophys. J. 4, 227 (1964). 